\title{
Testing the Contemporaneous and Causal Relationship between Trading Volume and Return in the Palestine Exchange
}

\author{
Dr. Marwan Darwish \\ Ass. of Vice President for Academic Affairs \\ Al-Quds Open University \\ P. O. Box 58100, Jerusalem, Palestine \\ Tel: 972-2-582-0876 E-mail: mdarwish@qou.edu
}

Received: September 30, 2011

doi:10.5539/ijef.v4n4p182

\author{
Accepted: February 21, 2012 \\ Published: April 1, 2012 \\ URL: http://dx.doi.org/10.5539/ijef.v4n4p182
}

\begin{abstract}
This study examines the causal relationship between return and trading volume in the Palestine Exchange. Using weekly trading volume and returns over the period from October 2000 to August 2010, the study employs GARCH $(1,1)$ model to test the existence of the positive contemporaneous relationship. The study found that the relationship preserves after taking heteroskedasticity into account. Moreover, the results of Granger causality test show that there is bidirectional Granger causality between returns and trading volume, regardless of the measures of trading volume used.
\end{abstract}

Keywords: Palestine Exchange, Return, Trading volume, Granger causality, GARCH(1,1)

\section{JEL Classifications: G15}

\section{Introduction}

The Palestine Exchange was established in 1996 as a private share holding company. It held its first session in February 1997 as an initial fully automated and electronic stock market. It has become a public shareholding company in February 2010 responding to principles of transparency and good governance, and operating under the supervision of the Palestinian Capital Market Authority, providing a market for trading securities and financial instruments. It is characterized by equity, transparency and competence, thereby serving and maintaining the interest of investors, in accordance with the securities laws and modern regulations, and forming a strong basis that ensure a fair-trading environment and attracting foreign investment free of any restrictions.

The Palestine exchange maintained sustained growth in terms of the number of listed companies, market value, and trading volumes. By the end of 2010 the number of listed companies, the number of shares traded, and the market value have raisin to (41 230 million, 451.2 millions) receptively, but the market Index had a relatively large amounted diversity, raising from 207.6 to 1128.6 at the end of 2005, then fell down to 489.6 by the end of 2010 . (www.pex.ps)

Empirical studies based on the trading data of the Palestine exchange are very rare or non-existent in Palestine. So after more than one decade of trading in Palestine Exchange, there is a potential to put into practice an empirical examination regarding the behaviors and dynamics of stock prices and trading volume. However, the purpose of this study is to investigate the contemporaneous and causal relationship between returns and trading volume, by applying Granger causality tests in the small emerging stock market of Palestine. In other words, the main purpose of this study is to test the hypothesis whether return-volume relation exists in the Palestine Exchange. Furthermore, this study addresses the issue of whether information about trading is useful in making the movement of the market. Such study has not been done in Palestine so far.

Testing for Causality is important; since it can help to better understand the microstructure of stock markets and its implications on other markets. While the empirical tests of return volume behavior are plentiful for developed stock markets, there is relatively less empirical research on emerging markets, but none relating to the Palestine Exchange. Moreover, this study will enable to uncover whether the return-volume relation in the Palestine Exchange exhibits different characteristics from those in developed markets. Understanding this relation has significant implications for regulators and other market participants. 
Many studies reported a contemporaneous correlation between stock returns and trading volume (Karpoff, 1987), but the empirical evidence on the causal relationship between the two variables is thus mixed, and in some cases, contradictory. Therefore, the relationship still remains a very interesting field for investigation in several stock markets.

The remainder of this study proceeds as follows. Section 2 provides a literature review of theoretical aspects and previous empirical research. Section 3 describes the data and the variables measurements. Section 4 presents the methodology and the empirical results, and section 5 provides some concluding comments.

\section{Literature Review}

\subsection{Theoretical Framework}

The relationship between stock return and trading volume has received considerable attention from financial economists over the past three decades. The importance of price volume relationship has been pointed out by Karpoff (1987), where he provides four important reasons to study the price volume relation:

First, this relationship provides insight into the structure of financial markets. It helps discriminate between competing theories on how information is disseminated in financial markets. Second, it is important for event studies that use a combination of price and trading volume data to draw inferences. Third, it is critical to debate over the empirical distribution of speculative prices. Fourth, price-volume relations have significant implications for research in the future markets. The research on the issue of price-volume relationship stresses a common belief that there is a positive relationship between price changes and trading volume in the financial markets. The rational for postulating this positive relation can be found in the basic supply and demand model, i.e. a change in demand induces a price change.

Some researchers found another theoretical explanation for the causal price-volume relation. One explanation states that price changes and trading volume relations are due to a mixture distribution, i.e. the mixture of distribution hypothesis (MDH) for Clark (1973), Epps and Epps (1976) and Harris (1986). This hypothesis shows that stock prices and trading volume are positively correlated because the variance of the price change on a single transaction is conditional upon the volume of that transaction. Therefore, the relation between price variability and trading volume is due to the joint dependence of price and volume on underlying common mixing variable, called the rate of information flow to the market. This implies that price and volume change simultaneously in response to new information.

The other explanation according to the sequential arrival information hypothesis proposed by Copeland (1976), and later extended by Jennings et.al. (1981), is that exists a positive bidirectional causal relationship between absolute values of price changes and trading volume. Sequential arrival of information hypothesizes that new information that reaches the market is not disseminated to all market participants simultaneously, but to one participant at a time. The final information equilibrium is established only after a sequence of intermediate or transitional equilibriums have occurred. Therefore, due to the sequence of information flow, lagged absolute returns may have the ability to predict current trading volume, and vice versa. Hiemstra and Jones (1994) argued that a sequential information flow results in lagged trading volume having predictive power for current absolute price changes, and lagged absolute price changes having predictive power for current volume.

The price-volume relationship can also be explained in terms of the noise- trader model of De Long et.al. (1990). This model postulates that the noise traders' activities are not based on economic fundamentals, but rather to cause a temporary miss pricing of stock prices in the short run. The price, however, moves toward its mean value in the long run in the absence of transitory component. In this model, the positive causal relationship running from stock returns to trading volume is consistent with the positive feedback trading strategy of noise traders who based their decisions on past price movements. A positive causal relationship from volume to price changes is consistent with the hypothesis that price changes are caused by the action of noise traders.

Furthermore, Lakonishok and Smidth (1989) showed that current volume can be related to past stock price changes due to tax-and non-tax-related trading motives. Therefore the dynamic (causal) relation for tax-related trading motives is negative, whereas certain non-tax-related trading motives are positive.

\subsection{Empirical Studies}

The empirical research on price-volume relationship is vast and mixed. Since the older literature was surveyed by Karpoff (1987), this study will concentrate on recent studies, particularly on studies in emerging markets. These studies also provide mixed evidence. While most of them produced evidence for bidirectional causality, which support for the sequential information arrival hypothesis, some evidence has been found for the mixture of distribution hypothesis. The following is a brief description of some of the recent studies. 
The evidence presented by Smirlock and Starks (1988), and Jain and Joh (1988) support an unidirectional Granger causality from returns to trading volume in the U.S. markets. Hiemstra and Jones (1994) applied linear and nonlinear causality testing to the U.S. stock market and found evidence of unidirectional Granger causality from Dow Jones stock returns to percentage changes in New York Exchange trading volume, but more importantly, they found significant bidirectional nonlinear causality between returns and volume. They also found evidence of nonlinear causality from volume to returns after controlling for volatility persistence in returns.

More recently, Chen et.al. (2001) examined the price - volume relation in nine developed equity markets. They found evidence that returns Granger cause volume for the U.S, Japan, U. K, Italy, Hong Kong, the Netherlands, France and Switzerland. Moreover, they reported significant bidirectional Granger causality for the markets of Switzerland, the Netherlands, Canada and Hong Kong, indicating that trading volume contributes some information to returns process. Lee and Rui (2002) also found that returns Granger cause trading volume in the U.S. and Japanese markets, but not for the U.K. market. Also they demonstrated that trading volume does not Granger cause stock market returns in the U.S., Japan and U.K. markets. They attributed this to the market efficiency.

Gunduz and Hatemi-J (2005) examined the dynamic relation between weekly stock prices and volume for Czech Republic, Hungary, Poland, Russia and Turkey stock markets. They found a bidirectional causality between returns and volume in Hungary and Poland, but an unidirectional causality running from market turnover to stock price in Poland, and the stock price unidirectional cause both volume and market turnover without any feedback in Russia and Turkey, but there is no causal relationship between the variables in the Czech Republic regarding market inefficiency, in addition the effects of different market characteristics on the stock price/volume relation.

Ajayi et. al. (2006) confirmed the unidirectional causality between price changes and trading volumes for six out of ten European stock markets, and bidirectional causality in Denmark, Portugal and Turkey, when they used nonlinear causality, but no causality in Switzerland. The same results for the case of Turkey, Kamath (2007) found evidence of a positive contemporaneous relation and a feedback bidirectional causality between volume and returns, when he used daily price changes and trading volume changes.

For the Asian emerging markets, Moosa and Al Loughani (1995) tested the price-volume relation in four Asian stock markets using monthly data. They found strong evidence for causality running from volume to absolute price changes, and from price changes to volume in Malaysia, Singapore and Thailand, but no causality for the Philippines due to the small size of this market. In another research, Silvapulle and Choi (1999) used linear and nonlinear causality tests to examine the dynamic relation between daily Korean stock returns and volume. They found a bidirectional linear and nonlinear Granger causality between stock returns and volume changes.

More recent studies, Henry and McKenzie (2006) found the same results for Hong Kong stock market; their evidence supports a nonlinear bidirectional relationship between volume and volatility. Pisedtasalasai and Gunasekarage (2007) found statistically significant causality running from stock return to trading volume for Indonesia, Malaysia, Singapore, and Thailand, and a significant causality running from trading volume to stock returns was detected only for Singapore. They didn't find any causal effect for the Philippines.

Also, Kamath and Wang (2006) found bidirectional causality in four out of six Asian stock markets, but in the case of Korean market they found evidence of causality running from returns to volume, and a diametrically opposite directional causality in the Taiwanese market. hese results were generally confirmed by Deo et.al. (2008), using daily data from seven Asia-pacific stock markets to examine the relationship between stock returns, volatility and trading volume. They found a bidirectional causality between returns and volume for Hong Kong, Indonesia, Malaysia and Taiwan stock markets.

In another Asian stock market Khan and Rizwan (2008) investigated the empirical relation between daily stock returns and trading volume in Pakistan's stock market. They found a positive contemporaneous relation between trading volume and return preserves after taking heteroskedasticity into account. Moreover, they found feedback bidirectional causality between the two variables. Mahajan and Singh(2009) examined the empirical relationship between return, volume and volatility dynamics using daily data from the Indian stock market. They found evidence of positive and significant correlation between volume and return volatility, and significant relationship of causality flowing from volatility to trading volume. Their study also detected one-way causality from return to volume, which is an indicative of a noise trading model of return- volume interaction in this market.

On the other hand, some studies focus on Latin American emerging markets. For example, Saatcioglu and Starks (1998) investigated price- volume relation for six Latin American stock markets and found evidence of unidirectional causality running from volume returns in all six markets. In another study, De Medeiros and Van Doornik (2006) examined the empirical relationship between stock returns, volatility and trading volume, using data from Brazilian stock market. They cannot find evidence of causal relationship between stock returns and trading 
volume in either direction. That means that short-run forecasts of current or future stock returns cannot be improved by knowledge of recent trading volume data and vice versa. In addition, they found a mutual Granger causality between returns volatility and trading volume, although more intensely from volume to volatility. Kamath (2008) examined price-volume relation in the Chilean stock market. His causality test results provide a clear evidence of daily returns Granger causing daily trading volume changes in the Chilean stock market.

Finally, in one of the African cases, Leon (2007) investigated the relation between daily stock return volatility and trading volume in the stock exchange in the West African Economic and Monetary Union (BRVM). The results of Granger Causality show that volume has predictive power to stock return volatility, regardless of the measure of volatility used. This is due to the maximum ceiling imposed price changes and non-synchronous trading, which hinder the transmission mechanism.

The literature search found some papers on a variety issues involving the Palestine Exchange. For example, Darwish (2009), and Awad and Daraghma (2009), tested the weak - form efficient market hypothesis for the Palestine Exchange, utilizing daily prices on the market and the five sectors indices. They found that the Palestine exchange is inefficient at the weak - form level. Darwish et. al. (2010) tested the relationship between risk and return, by applying GARCH $(1,1)$ model. They found that there is no significant positive relationship between risk and return in the Palestine Exchange. However, the price-volume relationship was not investigated in any published paper.

In summary, the majority of the previous studies have confirmed the existence of positive relationship between trading volume and returns. They also highlight that volume is a powerful indicator to predict the market .

Although emerging markets have shown progress in recent years, they have given mixed results about the return-volume relationship. However the literature is still lacking studies that inspect the relationship between these variables, especially in Palestine.

Moreover, the review of prior empirical evidences addressed some research questions: Is there contemporaneous correlation or causality relationships between returns and trading volume in the Palestine Exchange? If yes, then what is the direction and extent of relationship between those variables?

For this reason, this study comes to answer these questions taking variety of econometric techniques into consideration, and I believe that the present study contributes to the literature by enabling international investors to have a deeper insight about the characteristics of, and the relationship between return and volumes in the Palestinian emerging market.

\section{Data Description and Variable Measurements}

The data sample used in this study consists of weekly stock price index and trading volume of the Palestine Exchange (PE), covering the period from October 2000 to August 2010, for total of 486 pairs of relevant data. Weekly data were used because of the small market size, thin trading, and to avoid the day- of- the week effect, and the data were obtained from the Palestine Exchange database. The period after September 2000 was chosen because of the political and economic instability in the Palestinian territory before that date.

From the raw data of the closing Index values, the weekly rate of return $\left(\mathrm{R}_{\mathrm{t}}\right)$ was computed using the following equation:

$$
\mathrm{R}_{\mathrm{t}}=\operatorname{Ln}\left(\mathrm{P}_{\mathrm{t}} / \mathrm{P}_{\mathrm{t}-1}\right)
$$

Where $P_{t}$ is the closing index price on week $(t)$.

For the trading volume, different definitions and measures can be found in the previous studies, Jain and Joh (1988), Hiemstra and Jones (1994), Jiang and Kryzanowski (1997), Silvapulle and Choi (1999), and Lee and Rui (2002) have used raw value of trading volume, i.e. the number of shares traded. Chen and Zhou (2001) utilized logarithm of raw volume, Saatcioglu and Starks (1998) utilized market turnover, Gunduz and Hatemi-J (2005) utilized raw volume and market turnover. They have found the same results from utilizing different measures, Jiang and Kryzanowski (1997) noted that raw volume is a better proxy for information flow; therefore, this study utilizes raw volume, i.e. weekly number of shares traded, as a measure of trading.

The raw volume $\left(\mathrm{V}_{\mathrm{t}}\right)$ assumes only positive values. Therefore, in addition to raw volume, the study empirical tests also employ Kamath and Wang (2006) procedure by utilizing changes in raw volume, to take on account positive as well as negative values.

The changes in trading value $\left(\Delta V_{t}\right)$ were computed using the following equation:

$$
\Delta V_{t}=\operatorname{Ln}\left(\mathrm{V}_{\mathrm{t}} / \mathrm{V}_{\mathrm{t}-1}\right)
$$

Where $\mathrm{V}_{\mathrm{t}}$ is the raw trading volume. 
Table 1 presents the descriptive and basic statistics relating to the weekly returns and trading volumes. The statistics show that the sample means of return, trading volume and the changes in trading volume are positive. The measures of skewness and excess kurtosis indicate that the distribution of returns and trading volume are positively skewed and leptokurtic relative to a normal distribution, which is consistent with the presence of GARCH effects. The Jarque-Bera normality test rejects normality of all series at $1 \%$ level. The autocorrelation coefficient (LB) up to 36 lags is statistically significant which indicates that all series suffer from serial correlation.

\section{Methodology and Empirical Results}

\subsection{Unit Root Test}

Before applying any model to the data, the study adopts a test for a unit root to ensure that every variable is stationary, and to avoid spurious regression. The testing for a unit root is based on Augmented Dickey- Fuller (1979) (ADF) test, and Phillips-Perron (1988) (PP) test. ADF and PP tests are used with trend and without trend.

Table 2 reports the results of ADF and the PP tests for unit root. The results show that the null hypothesis that return and trading volume series are nonstationary (i.e. has a unit root) is rejected for all series. This confirms that all series tested are stationary and, therefore, useful for further statistical analysis. The implication of these findings is that testing for causality between return and volume should be based on unrestricted VAR approach.

\subsection{Contemporaneous Relationships}

The study examines the contemporaneous relation between return and trading volume before testing Granger causality. With contemporaneous test, the study examine the notion that rising market indexes are accompanied by rising volume, whereas declining market is accompanied by falling volume. For this purpose the following regression equations were estimated:

Panel A:

$$
R_{t}=\alpha_{1}+\beta_{1} R_{t-1}+b_{1} V_{t}+\varepsilon_{t 1}
$$

Panel B:

$$
R_{t}=\alpha_{2}+\beta_{2} R_{t-1}+b_{2} \Delta V_{t}+\varepsilon_{t 2}
$$

Where $R_{t}$ is return at time $\mathrm{t}$, and $V_{t}, \Delta V_{t}$ are the raw trading volume and the changes in trading volume at time $\mathrm{t}$ respectively, $R_{t-1}$ is included in the equations to account for serial correlation in returns series.

The results reported in Table 3. indicate a positive contemporaneous relation between returns and trading volume, and between returns and the changes in trading volume. These results are consistent with most of the previous studies, for example: Lee and Rui (2000), De Medeiros and Van Doornik (2006), Khan and Rizwan (2008). The results provide a support for notion that rising markets are accompanied by rising volume and declining markets are accompanied by falling volume, and that is consistent with the theoretical model that implies that information content of volume affects future stock return. This evidence on the Palestine Exchange is consistent with the evidence reported for many of the developed, as well as, emerging markets.

The Ljung-Box $(\mathrm{LB}(\mathrm{Q}))$ statistics up to 36 lags are statistically insignificant, which indicate that the models do not suffer from the problem of serial correlation. While ARCH-LM test indicates the presence of ARCH effect.

For further investigation about the relationship between trading volume and returns, and to test whether the positive contemporaneous relation still exists after controlling for non-normality of error distribution, the study used a Generalized Autoregressive Conditional Heteroskedasticity (GARCH) model. Following Lee and Rui (2000), and Khan and Rizwan (2008), and according to Darwish et.al. (2010), the following $\operatorname{GARCH}(1,1)$ models are appropriated for the Palestine exchange:

Panel A:

$$
\begin{gathered}
R_{t}=\alpha_{1}+\beta_{1} R_{t-1}+b_{1} V_{t}+\varepsilon_{t} \\
\varepsilon_{t}^{2} \mid\left(\varepsilon_{t-1}^{2}, \varepsilon_{t-2}^{2}, \ldots\right) \approx \mathrm{N}\left(0, h_{t}\right) \\
h_{t}=\omega_{0}+\omega_{1} \varepsilon_{t-1}^{2}+\omega_{2} h_{t-1}
\end{gathered}
$$

Panel B:

$$
R_{t}=\alpha_{2}+\beta_{2} R_{t-1}+b_{2} \Delta V_{t}+v_{t}
$$




$$
\begin{aligned}
& v_{t}^{2} \mid\left(v_{t-1}^{2}, v_{t-2}^{2}, \ldots\right) \approx \mathrm{N}\left(0, h_{t}\right) \\
& h_{t}=\gamma_{0}+\gamma_{1} v_{t-1}^{2}+\gamma_{2} h_{t-1}
\end{aligned}
$$

Where $h_{t}$ is the variance of the error term, $\varepsilon_{t}\left(v_{t}\right)$, at time t. $\omega_{0}, \gamma_{0}$ are constant and $\omega, \gamma_{1}$ are coefficient that relate the past values of squared residuals, $\varepsilon_{t-1}^{2}$, and $v_{t-1}^{2}$ relate to current volatility, and $\omega_{2}, \gamma_{2}$ are coefficient that relate current volatility to the volatility of the previous period.

The results reported in Table 4, indicate that GARCH model is an attractive representation of weekly stock behavior, and successfully capturing the temporal dependence of return volatility. GARCH parameters are statistically significant, and the coefficients in the conditional variance equation (i.e., $\omega_{1}$ and $\gamma_{1}$ ) are smaller than the $\omega_{2}$ and $\gamma_{2}$, respectively. This implies that small market surprises induce relatively large revisions in future volatility. Moreover, the coefficients of regressing returns on trading volume and changes in trading volume are positive and statistically significant by using GARH $(1,1)$ model. The Ljung-Box (LB(Q)) statistics up to 36 lags are statistically insignificant, which indicate that there is no serial correlation in the models. While Wald chi-square statistics are significant, indicating that the parameters associated with the explanatory variables are statically different from zero. So the positive contemporaneous relationship between trading volume and return preserves after taking heteroskedasticity into account. These findings are consistent with the finding of Lee and Rui (2000) in the Chinese stock market and with Khan and Rizwan (2008) in the Pakistan market.

\subsection{Test for Granger Causality}

Our investigation covers not only contemporaneous but also causal relationship, with causality test the study examine if the changes in volume cause return to change even when controlled for the past changes in the returns, and vice versa. The unit root test shows that we can test for Granger causality between returns and trading volume without making error correction models, so the study investigates causality between the two variables in both directions following bivariate Vector Autoregressive (VAR) models:

$$
\begin{array}{r}
R_{t}=\alpha_{R}+\sum_{i=1}^{n} \alpha_{i} R_{t-i}+\sum_{i=1}^{n} \beta_{i} V_{t-i}+\varepsilon_{R, t} \\
V_{t}=\alpha_{v}+\sum_{i=1}^{n} \alpha_{i} V_{t-i}+\sum_{i=1}^{n} \beta_{i} R_{t-i}+\varepsilon_{V, t}
\end{array}
$$

And for the changes in the trading volume:

$$
\begin{gathered}
R_{t}=\alpha_{R}+\sum_{i=1}^{n} \alpha_{i} R_{t-i}+\sum_{i=1}^{n} \beta_{i} \Delta V_{t-i}+\varepsilon_{R, t} \\
\Delta V_{t}=\alpha_{v}+\sum_{i=1}^{n} \alpha_{i} \Delta V_{t-i}+\sum_{i=1}^{n} \beta_{i} R_{t-i}+\varepsilon_{\Delta V, t}
\end{gathered}
$$

The null hypothesis in Granger causality test is that $R_{t}\left(V_{t}\right)$ does not Granger cause $V_{t}\left(R_{t}\right)$ for the equation $7 \mathrm{a}$ and $8 \mathrm{a}$, and $R_{t}\left(\Delta V_{t}\right)$ does not granger cause $\Delta V_{t}\left(R_{t}\right)$ for the equations $7 \mathrm{~b}$ and $8 \mathrm{~b}$. The null hypothesis in the above-mentioned equation is mathematically represented by $\mathrm{H}_{0}: \beta_{i}=0$ for all (i), and the test statistic is a standard Ftest.

To ensure that the models are not including unnecessary lags, the researcher used Akaike information criterion (AIC), Schwarz information criterion (SC), F- Statistic and adjusted $\mathrm{R}^{2}$ statistic. After trying many combinations for number of lags between 1 and 20, the optimal VAR(10) was used. Thus the right side of equations $7 \mathrm{a}, \mathrm{b}$ and $8 \mathrm{a}, \mathrm{b}$ require estimating 21 coefficients. Instead of providing the entire 21 coefficient. Table 5. presents the intercept, the first lag, and the tenth lag of the returns and trading volume, along with F-Statistic and the adjusted $\mathrm{R}^{2}$ statistic.

Panel A, Table 5, shows that the influence of lagged trading volume on returns is weak but significant at $1 \%$ level on at least one lag, and the influence of lagged returns on trading volume is negative and significant at $5 \%$ level, at least on one lag. 
Panel B, Table 5, shows that the influence of lagged changes in trading volume on returns is significant at $1 \%$ level, at least on one lag, and the influence of lagged returns on lagged changes in trading volume is positive and significant at $10 \%$ level, at least on one lag.

To take a better decision about the bidirectional causality between trading volume and returns Table 6 presents the results of Granger causality based on VAR (10) results shown in Table 5.

The results in Table 6 indicate a clear evidence of bidirectional Granger causality in the Palestine Exchange, which mean that returns Granger cause trading volume and trading volume Granger cause returns, regardless of how trading volume is defined or measured.

These results are consistent with those of Moosa and A-Loughani (1995), Silvapulle and Choi (1999), Khan and Rizwan (2008), which reported bidirectional causal relationship to some Asian stock markets, and some emerging European markets such as Hungary, Poland, and Russia, (Gunduz and Hatemi-J 2005), and to small developed markets such as Switzerland, Netherlands, Turkey, and Hong Kong (Chen et. al. (2001), Ajayi et.al. (2003) and Kamath (2003). But the results are not consistent with the previous evidence from developed markets, such as Hiemstra and Jones (1994) and Lee and Rui (2002). They have documented that volume does not Granger cause stock market returns in developed markets. Because the microstructure and institutional factors regarding small stock market of Palestine are different from the developed stock markets. Silvapulle and Choi (1999) argue that institutional, organizational and structural factors have effect on the behavior of price-volume relation. However, trading in the Palestine exchange is much lower than in most developed countries.

The findings of bidirectional causality can be explained theoretically: Volume, which implies information, leads to price changes, and large positive price changes that imply higher capital gain, encourage transactions by traders leading to increase in volume. Moreover, the majority of stock market Participants in Palestine are short-term investors, who frequently engage in speculative activities, thus their behavior can be characterized by over-reaction to new information, and lacking fundamental analysis.

The economic interpretation of the results concerning the findings of bidirectional causality seems to be consistent with the noise trading model of De Long et. al. (1990); a positive causal relationship running from price to volume, consistent with a positive feedback trading strategy of noise traders who base their decisions on past price movements, and also positive causal relationship from volume to price, consistent with the hypothesis that price changes are caused by the action of noise traders. A greater influence of noise traders is possibly due to the delaying frequent and thin trading.

\section{Conclusion}

This study investigated the relationship between trading volume and returns using weekly data from the Palestine exchange over the period from October 2000 to August 2010. We found evidence of a significant contemporary relationship between trading volume and return, and indicating that information content of volume affects future stock return. This evidence is consistent with the evidence reported by studies on many developed and emerging markets.

We also found evidence of bidirectional Granger causality between trading volumes and returns regardless of the measures of trading volume used. The theoretical explanation of this finding is that volume which implies information leads to price changes, and large positive price changes that imply higher capital gain, encourage transactions by traders to increase in volume. Moreover these findings of bidirectional causality are consistent with the noise trading model of De Long et.al.(1990).

Our findings provide evidence of positive contemporaneous relationship between volume and returns. Granger causality tests also confirmed that volume added a predictive power for future returns in presence of current and past returns, and vice versa.

It is concluded that the past information of trading volume is useful for prediction of stock price, and vice versa. The study suggests that regulators and market participants can use past information for monitoring the stock price movement in the market.

Some of the limitations of this study is that we have employed the linear Granger causality test, and normal volume and returns. Non-normality hypothesized to have different effects, so there is a need for further study considering nonlinear mechanism and empirical regularities.

However, the finding of this study is subject to the period and data selected, and the results may therefore change if the study period and data change. 


\section{Acknowledgement}

I would like to thank the Editor and two anonymous reviewers for their many insightful and helpful comments and suggestions. Any errors are entirely my own.

\section{References}

Ajayi, R. A., Mehdian, S., \& Mougoue, M. (2006). The empirical relation between price changes and trading volumes: Further evidence from European stock markets. Alliance Journal of Business Research, 1, 3-20.

Awad, I., \& Daraghma, Z. (2009). Testing the weak - form efficiency of the Palestinian securities market. International Research Journal of Finance and Economics, 32, 7-17.

Chen, C., \& Zhou, Z. (2001). Stock returns, volatility, and trading volume: Evidence from the Chinese stock markets. International Journal of Business, 6, 67- 86.

Chen, G., Firth M., \& Rui, O. M. (2001). The Dynamic relation between stock returns, trading volume, and volatility. Financial Review, 38, 153-174. http://dx.doi.org/10.1111/j.1540-6288.2001.tb00024.x

Clark, P. K. (1973). A subordinated stochastic process model with finite variance for speculative prices. Econometrica, 41,135-155. http://dx.doi.org/10.2307/1913889

Copeland, T. E. (1976). A model of asset trading under the assumption of sequential information arrival. Journal of Finance, 31, 1149-1168. http://dx.doi.org/10.2307/2326280

Darwish, M. J. (2011). Testing the weak - form efficiency for Palestine stock market. Journal of Al-Quds Open University for Research and Studies, 23, 83-114.

Darwish, M. J, Al - Doori, M. A., \& Al-Horani A. A. (2010). Testing the relationship between risk and return in the Palestine securities Exchange. Interdisciplinary Journal of Contemporary Research in Business, 2, 265-276.

De Long, J., Shleifer, A., Summers, L., \& Waldmann, R. (1990). Positive feedback, investment strategies, and destabilizing rational speculation. Journal of Finance, 45, 379-395. http://dx.doi.org/10.2307/2328662

De Medeiros, O. R., \& Van Doornik, B. F. (2006). The empirical relationship between stock returns, return volatility and trading volume in the Brazilian stock market. a working paper series, university of Brasilia.

Deo, M., Srinivasan K., \& Devanadhen, K. (2008). The empirical relationship between stock returns, trading volume, and volatility: Evidence from select Asia -Pacific stock market. European Journal of Economics, Finance and Administrative Sciences, 12, 58-68.

Epps, T. W., \& Epps, M. L. (1976). The stochastic dependence of security price changes and transaction volumes: Implications for the mixture of distributions hypothesis. Econometrica, 44, 305-321. http://dx.doi.org/10.2307/1912726

Granger, C. W. J. (1969). Investigating causal relations by econometric models and cross- spectral methods. Econometrica, 37,424-438. http://dx.doi.org/10.2307/1912791

Gunduz, L., \& Hatemi-J, A. (2005). Stock price and volume relation in emerging markets . Emerging Markets Finance and Trade, 41, 29-44.

Harris, L. E. (1986). Cross-security tests of the mixture of distributions hypothesis. Journal of Financial and Quantitative Analysis, 21, 39-46. http://dx.doi.org/10.2307/2330989

Henry, O. T., \& McKenzie, M. (2006). The impact of short selling on the price-volume relationship: Evidence from Hong Kong. Journal of Business, 79, 671-691. http://dx.doi.org/10.1086/499135

Hiemstra, C., \& Jones, J. D. (1994). Testing for Linear and Nonlinear Granger causality in stock price-volume relation. Journal of Finance, 49, 1639-1664. http://dx.doi.org/10.2307/2329266

Jain, P. C., \& Joh, G. H. (1988). The dependence between hourly prices and trading volume. Journal of Financial and Quantitative Analysis, 23, 269-283. http://dx.doi.org/10.2307/2331067

Jennings, R. H., Starks L., \& Fellingham, J. (1981). An equilibrium model of asset trading with sequential information arrival. Journal of Finance, 36, 143-161. http://dx.doi.org/10.2307/2327469

Jiang, L., \& Kryzanowski, L. (1997). Trading activity, quoted liquidity, and stock volatility. Multinational finance Journal, 3, 199-227.

Kamath, R. R. (2007). Investigating causal relations between price changes and trading volume changes in the Turkish market. ASBBS E-Journal, 3, 30-40. 
Kamath, R. R. (2008). The price-volume relationship in the Chilean stock market. International Business and Economic Research Journal, 7, 7-13.

Kamath, R. R., \& Wang, Y. (2006). The causality between stock index returns and volumes in the Asian equity markets. Journal of International Business Research, 5, 63-74.

Karpoff, J. M. (1987). The relation between price changes and trading volume: A survey. Journal of Financial and Quantitative Analysis, 22, 109-126. http://dx.doi.org/10.2307/2330874

Khan, S. U., \& Rizwan, F. (2008). Trading volume and stock returns Evidence from Pakistan's stock market. International Review of Business Research papers, 4, 151-162.

Lakonishok J. \& Smidth, S. (1989). Past prices changes and current trading volume. Journal of Portfolio Management, 15, 18-24. http://dx.doi.org/10.3905/jpm.1989.409223

Lee, C. F., \& Rui, O. M. (2000). Does trading volume contain information to predict stock returns? Evidence from China's stock markets. Review of quantitative finance and accounting, 14, 341-360. http://dx.doi.org/10.1023/A:1008319826042

Lee, B. S., \& Rui, O. M. (2002). The dynamic relationship between stock returns and trading volume: Domestic and cross - country evidence. Journal of Banking and finance, 26, 51-78. http://dx.doi.org/10.1016/S0378-4266(00)00173-4

Leon, N. K. (2007). An empirical study of the relation between stock return volatility and trading volume in the BRVM. African Journal of Business Management, 1, 176-184.

Mahajan S. \& Singh, B. (2009). The empirical investigation of relationship between return, volume, and volatility dynamics in Indian stock market. Eurasian Journal of Business and Economics, 2,113-137.

Moosa, I. A., \& Al - Loughani, N. E. (1995). Testing the price - volume relation in emerging Asian stock markets. Journal of Asian Economics, 6, 407-422. http://dx.doi.org/10.1016/1049-0078(95)90007-1

Pisedtasalasai, A., \& Gunasekarage, A. (2007). Causal and dynamic relationships among stock returns, return volatility, and trading volume: Evidence from emerging markets in South-East Asia. Asia-Pacific Financial Markets, 14, 277-297. http://dx.doi.org/10.1007/s10690-008-9063-3

Saatcioglu, K., \& Starks, L. T. (1998). The stock price - volume relationship in emerging stock markets: The case of Latin America . International Journal of forecasting, 14,215-225. http://dx.doi.org/10.1016/S0169-2070(98)00028-4

Silvapulle, P., \& Choi, J. (1999). Testing for linear and nonlinear Granger causality in the stock price-volume relation: Korean evidence. Quarterly Review of Economics and Finance, 39, 59-76. http://dx.doi.org/10.1016/S1062-9769(99)80004-0

Smirlock, M., \& Starks, L. T. (1988). An empirical analysis of the stock price - volume relationship, Journal of Banking and Finance, 12, 31-41. http://dx.doi.org/10.1016/0378-4266(88)90048-9

Table 1. Descriptive statistics

\begin{tabular}{|ccccccc|}
\hline Variable & Mean & Std. Dev. & Skewness & Kurtosis & Jarque-Bera & LB (Q):36 \\
\hline$R_{t}$ & .0013 & 0.0409 & 0.2596 & 4.9933 & $85.9156^{*}$ & $54.76^{*}$ \\
\hline$V_{t}$ & 846125.1 & 1210033 & 5.9078 & 65.1643 & $81075.55^{*}$ & $354.84^{*}$ \\
\hline$\Delta V_{t}$ & -0.0003 & 1.0526 & -0.1855 & 4.5468 & $51.2354^{*}$ & $124.54^{*}$ \\
\hline
\end{tabular}

* Note: Significant at $1 \%$ level 
Table 2. Unit root test in the level

\begin{tabular}{|lllllll|}
\hline \multirow{2}{*}{ Variable } & \multicolumn{2}{c}{ ADF } & \multicolumn{2}{c|}{ PP } \\
\cline { 2 - 7 } & None & Intercept & Trend and intercept & None & Intercept & Trend and intercept \\
\hline$R_{t}$ & -18.748 & -18.745 & -18.7244 & -19.7562 & -19.7413 & -19.7246 \\
\hline$V_{t}$ & -3.5429 & -8.6519 & -9.8777 & -16.3538 & -19.2669 & -19.2649 \\
\hline$\Delta V_{t}$ & -16.691 & -16.679 & -16.6559 & -87.9158 & -88.145 & -88.0135 \\
\hline
\end{tabular}

Note: The $1 \%$ critical values of the ADF and PP tests are -3.4436 (without trend) and -3.9771 (with trend). A significant test statistic indicates the rejection of the null hypothesis, which is nonstationary in both tests.

Table 3. Regression of weekly trading volume on returns

\begin{tabular}{|llllll|}
\hline Panel A: $R_{t}=\alpha_{1}+\beta_{1} R_{t-1}+b_{1} V_{t}+\varepsilon_{t 1}$ & & \multicolumn{3}{l|}{ Panel B: $R_{t}=\alpha_{2}+\beta_{2} R_{t-1}+b_{2} \Delta V_{t}+\varepsilon_{t 2}$} & Coefficient \\
\hline Variable & Coefficient & Z-Statistic & Variable & Z-Statistic \\
\hline$\alpha_{1}$ & -0.00322 & -1.4506 & $\alpha_{2}$ & 0.00108 & $0.5974 *$ \\
\hline $\boldsymbol{\beta}_{1}$ & 0.1257 & $2.8111^{*}$ & $\beta_{2}$ & 0.1535 & $3.4600^{*}$ \\
\hline $\boldsymbol{b}_{1}$ & $5.13 \times 10^{-9}$ & $3.3912^{*}$ & $b_{2}$ & 0.0068 & $3.9434^{*}$ \\
\hline LB (Q):36 & 37.458 & & LB (Q):36 & 35.98 & \\
\hline ARCH- LM test & $18.6751^{*}$ & & ARCH- LM test & $17.436^{*}$ & \\
\hline
\end{tabular}

*Note: significant at $1 \%$ level

Table 4. GARCH Results

\begin{tabular}{|c|c|c|c|c|c|}
\hline \multicolumn{3}{|c|}{$\begin{array}{l}\text { Panel A: } R_{t}=\alpha_{1}+\beta_{1} R_{t-1}+b_{1} V_{t}+\varepsilon_{t} \\
h_{t}=\omega_{0}+\omega_{1} \varepsilon_{t-1}^{2}+\omega_{2} h_{t-1}\end{array}$} & \multicolumn{3}{|c|}{$\begin{array}{r}\text { Panel B: } R_{t}=\alpha_{2}+\beta_{2} R_{t-1}+b_{2} \Delta V_{t}+v_{t} \\
h_{t}=\gamma_{0}+\gamma_{1} \varepsilon_{t-1}^{2}+\gamma_{2} h_{t-1}\end{array}$} \\
\hline Variable & Coefficient & Z-Statistic & Variable & Coefficient & Z-Statistic \\
\hline$\alpha_{1}$ & -0.00144 & -1.1189 & $\alpha_{2}$ & 0.0009 & 0.7164 \\
\hline$\beta_{1}$ & 0.13519 & $6.6899^{*}$ & $\beta_{2}$ & 0.1627 & $6.9754 *$ \\
\hline$b_{1}$ & $2.83 \times 10^{-9}$ & $4.7982 *$ & $b_{2}$ & 0.00393 & $2.8275^{*}$ \\
\hline$\omega_{0}$ & 0.00014 & $5.1216^{*}$ & $\gamma_{0}$ & 0.00014 & $5.4846^{*}$ \\
\hline$\omega_{1}$ & 0.3651 & $5.2528^{*}$ & $\gamma_{1}$ & 0.3403 & $5.1032 *$ \\
\hline$\omega_{2}$ & 0.6020 & $12.5398^{*}$ & $\gamma_{2}$ & 0.613 & $12.7725^{*}$ \\
\hline LB (Q):36 & \multicolumn{2}{|c|}{31.259} & \multicolumn{2}{|l|}{ LB (Q):36 } & 31.736 \\
\hline Log likelihood & \multicolumn{2}{|c|}{942.1092} & \multicolumn{2}{|c|}{ Log likelihood } & 942.7206 \\
\hline Wald $\chi^{2}(1)$ & \multicolumn{2}{|c|}{$23.023^{*}$} & \multicolumn{2}{|l|}{ Wald $\chi^{2}(1)$} & $7.9945^{*}$ \\
\hline
\end{tabular}

*Note: significant at $1 \%$ level 
Table 5. Vector Autoregressive Estimates

\begin{tabular}{|c|c|c|c|c|c|c|c|}
\hline \multicolumn{4}{|c|}{$\begin{array}{l}\text { Panel A: } \\
\text { Dependent Variable }\end{array}$} & \multicolumn{4}{|c|}{$\begin{array}{l}\text { Panel B: } \\
\text { Dependent Variable }\end{array}$} \\
\hline \multicolumn{2}{|c|}{$\boldsymbol{R}_{t}$} & \multicolumn{2}{|c|}{$V_{t}$} & \multicolumn{2}{|c|}{$\boldsymbol{R}_{t}$} & \multicolumn{2}{|c|}{$\Delta \mathbf{V}_{\mathbf{t}}$} \\
\hline Coeff. & Value & Coeff. & Value & Coeff. & Value & Coeff. & Value \\
\hline$\alpha_{R}$ & $-.0039 * * *$ & $\alpha_{\mathrm{v}}$ & 207516.4 & $\alpha_{R}$ & .0006 & $\alpha_{\mathrm{DV}}$ & -.0035 \\
\hline$\alpha_{1}$ & $0.0975^{* *}$ & $\alpha_{1}$ & $0.168^{*}$ & $\alpha_{1}$ & $0.1363 *$ & $\alpha_{1}$ & $-0.621 *$ \\
\hline$\alpha_{10}$ & 0.0423 & $\alpha_{10}$ & $.098 * *$ & $\alpha_{10}$ & .0523 & $\alpha_{10}$ & -.0575 \\
\hline$\beta_{1}$ & $1.57 \times 10^{-9}$ & $\beta_{l}$ & $1890218^{* * *}$ & $\beta_{l}$ & $-0.0055^{*}$ & $\beta_{1}$ & $1.384 * * *$ \\
\hline$\beta_{10}$ & $-3.96 \times 10^{-9 *}$ & $\beta_{10}$ & 2654723 & $\beta_{10}$ & $0.0038^{* *}$ & $\beta_{10}$ & .3064 \\
\hline F-Stat. & $3.94 *$ & F-Stat. & $5.26^{*}$ & F-Stat. & $3.51 *$ & F-Stat. & $11.10^{*}$ \\
\hline $\operatorname{adj} R^{2}$ & 0.076 & $\operatorname{adj} R^{2}$ & 0.152 & $\operatorname{adj} R^{2}$ & .06 & $\operatorname{adj} R^{2}$ & 0.30 \\
\hline
\end{tabular}

$*, * *, * *$ Note: $\quad$ significant at $1 \%, 5 \%$ and $10 \%$ level respectively

Table 6. Granger Causality

\begin{tabular}{|llccc|}
\hline \multicolumn{1}{|c}{ Panel } & \multicolumn{1}{c}{ Null Hypothesis } & Obs. & F-Statistic & Prob. \\
\hline Panel A. & V doesn't Granger cause R & 476 & 2.595 & 00046 \\
& R doesn't $\quad$ Granger cause V & & 1.79 & 0.075 \\
\hline Panel B. & $\Delta$ V doesn't Granger cause R & 476 & 1.81 & 0.057 \\
& R doesn't Granger cause $\Delta V$ & & 1.79 & 0.042 \\
\hline
\end{tabular}

